atmospheric carbon monoxide remains to be carried out.

That there are other sources besides the oceans is the chief conclusion to emerge from the latest work of Swinnerton et al. (Science, 172, 943; 1971). These workers have now found that in various samples of rainwater there is a high degree of supersaturation of carbon monoxide relative to the partial pressure of carbon monoxide in the atmosphere. The samples were from three widely separated and very different environments in the United States and the Pacific Ocean. The first set of samples was in Washington DC, in the heart of civilization where atmospheric pollution can be considered significant; the set was taken aboard a ship in the Pacific with the collector well forward of the funnels and while the ship was heading into the wind; the third set was from two different sites in Hawaii-in Hilo, the largest community on Hawaii, and in the interior of the island upwind of active volcano sites. All samples were then analysed immediately for both carbon monoxide and methane with the exception of those from the Hawaiian interior which were analysed within two hours of collection. At all sites air samples were also taken and analysed similarly.

As might be expected the carbon monoxide concentrations in the air samples were indicative of the environments. Thus in Washington they were high and very variable, in the Pacific they were much more constant and low (on average about fifteen times lower than in Washington), in the Hawaiian interior they were slightly higher than in the Pacific, and in Hilo concentrations were about twice as high as those in the Pacific, in accordance with a small town environment. In the Pacific, where pollution can be considered negligible, the absolute concentrations of carbon monoxide were about 0.10 p.p.m. of air. At all sites, however, the rainwater was supersaturated with carbon monoxide with respect to the atmospheric concentration, up to factors of 200. Even more surprisingly, the supersaturation was highest in regions where pollution was least-in the Hawaiian interior and over the Pacific. For methane, however, the story was completely different. In all cases the concentration of methane in rainwater was in rough equilibrium with the partial pressure of methane in the atmosphere.

Why is rainwater supersaturated with carbon monoxide? A clue may come from the observed variations of supersaturation with height. In the Hawaiian interior at altitudes of 2,000 to 5,000 feet the degree of supersaturation is significantly higher than in Hilo which is roughly at sea level. This is in accordance with the expectation that rain- water will lose supersaturation as it falls through the atmosphere; but by the same token it suggests that the source of the carbon monoxide is in the region where the rain is formed-that is, in the clouds.

Swinnerton and his colleagues then go on to suggest two possible mechanisms for the formation of excess carbon monoxide. The first is a possible photochemical oxidation of organic matter. It is now known that rainwater contains low concentrations of organic matter; and Wilson et al. (Science, 168, 1577; 1970) recently showed that photochemical oxidation of organic matter leads to the produc- tion of carbon monoxide in seawater. The same process could take place in rainwater.

The other possibility discussed is electric discharge in the clouds leading to a slight dissociation of carbon dioxide. Laboratory studies have already shown that such a process is possible, although Swinnerton et al. consider that it would not be able to account fully for the observed atmospheric concentrations of carbon monoxide. Both these mechanisms are, of course, speculative. But what does seem certain is that by one means or another the atmosphere itself is another natural source of carbon monoxide.

\title{
The Migration of Hawaiian Volcanism
}

THE Hawaiian Island Chain has long been a source of fascination to geologists, from the time that Dana visited it as part of the US Exploring Expedition (1838-1842) to the more recent use of Hawaiian volcanic lavas for determining the outline of the geomagnetic polarity-time scale. It was Dana, in fact, who first noted that the active volcanoes at the extreme south-east of the chain give way to extinct volcanoes which became progressively more eroded towards the north-west. $\mathrm{He}$ suggested, as a result, that the centre of eruption had migrated to the southeast-a view which is still held by geologists today notwithstanding the advent of the new global tectonics.

In one sense, of course, the very existence of the Hawaiian Chain and others like it in the Pacific is an anomaly as far as global tectonics is coricerned. The principal sources of volcanic activity lie along the worldwide ridge-trench system; but the Pacific island and seamount chains lie on large, nearly straight, aseismic ridges which strike roughly at right angles to the East Pacific Rise but occur a long way from it. How then, if at all, do such chains fit into the pattern of seafloor spreading and plate tectonics? As Tuzo Wilson (Nature, $197,536 ; 1963)$ pointed out, the facts are not necessarily irreconcilable. He visualized a spreading Pacific Ocean crust moving over a deep localized magma source. In such a scheme a volcano on the crust would ultimately become dissociated and get carried away from its source in a northwesterly direction, and a new volcano would arise in its place. This does, of course, beg the question of the nature of the magma source; but given that the source exists its behaviour is entirely explicable in terms of seafloor spreading.

Wilson's qualitative view is now widely accepted. In next Monday's
Nature Physical Science, however, McDougall takes Wilson's model considerably further by putting it on a more quantitative basis. There is now so much radiometric age data available from the Hawaiian Chain that McDougall has been able to make a pretty good estimate of the migration rate of the Hawaiian centre of volcanism and thus compare it with previously determined rates of spreading of the lithosphere away from the East Pacific Rise. Thus he determines the migration rate from the age of cessation of eruption of the tholeiitic magmas from each of the volcanoes now extinct in the Chain and the distance from the currently active volcano on Hawaii itself. The average figure he then comes up with is $15.2 \pm$ $1.4 \mathrm{~cm}$ per year. The magnitude of the standard deviation here shows that during at least the past 16 million years the migration rate has remained remarkably constant, which suggests, in turn, uniformity in the processes involved in the formation of the chain.

In comparison, the rate of seafloor spreading away from the East Pacific Rise in a roughly north-east direction is about $6 \mathrm{~cm}$ per year, or somewhat less than half of the migration rate of the volcanic centre. This suggests that, by the seafloor spreading hypothesis, the return flow of material in the asthenosphere towards the East Pacific Rise is taking place with roughly the same velocity as the flow of the lithosphere in the opposite direction--and that the source of Hawaiian volcanism lies right in that part of the upper mantle (the asthenosphere) which contains the return flow. This accords well with theory. The asthenosphere, which is thought to correspond roughly with the low velocity seismic zone, is commonly supposed to be a layer of partial melting in the mantle which would thus serve as an obvious source of magmatism. 